\title{
25 Research Square \\ Towards a Universal Definition of Disease Activity Score Thresholds: The AS135 Score
}

Nathan Foulquier

université de bretagne occidentale, Inserm UMR 1227, CHU brest, France

\section{Baptiste Chevet}

université de bretagne occidentale, Inserm UMR 1227, CHU brest, France

\section{Guillermo Carvajal Alegria}

université de bretagne occidentale, Inserm UMR 1227, CHU brest, France

\section{Léa Saraux}

Centre Hospitalier Régional Universitaire de Brest

\section{Valérie Devauchelle-Pensec}

université de bretagne occidentale, Inserm UMR 1227, CHU brest, France

\section{Pascal Redou}

LATIM, Laboratoire de Traitement de I'Information Médicale, Inserm, UMR 1101, Université de Brest, Brest, France

Alain Saraux ( $\square$ alain.saraux@chu-brest.fr)

université de bretagne occidentale, Inserm UMR 1227, CHU brest, France

\section{Research Article}

Keywords: Artificial intelligence, mobile phone, disease activity, rheumatology

Posted Date: November 11th, 2021

DOI: https://doi.org/10.21203/rs.3.rs-966560/v1

License: (c) (i) This work is licensed under a Creative Commons Attribution 4.0 International License. Read Full License 


\section{Abstract \\ Background}

Many study groups have developed scores to reflect disease activity. The result of this fragmented process is a multitude of disease activity scores, even for a single disease.

\section{Design:}

To identify and standardize disease activity scores in rheumatology, we conducted a literature review on disease activity criteria using both a manual approach and in-house computer software (BIBOT) that applies natural language processing to automatically identify and interpret important words in abstracts published in English between 1.1.1975 and 31.12.2018. We selected activity scores with cut-off values divided into four classes (remission and low, moderate and high disease activity). We used a linear interpolation to map disease activity scores to our new score, the AS135, and developed a smartphone application to perform the conversion.

\section{Results}

A total of 108 activity criteria from various fields were identified, but it was in rheumatology that we found the most pronounced separation into four classes. We built the AS135 score modification for each selected score using a linear interpolation of the existing criteria. The score modification was defined on the interval $[0,10]$, and values of 1 , 3 and 5 were used as thresholds. These arbitrary thresholds were then associated with the thresholds of the existing criteria, and an interpolation was calculated, allowing conversion of the existing criteria into the AS135 criterion. Finally, we created a mobile application.

\section{Conclusion}

We developed an application for clinicians that enables the use of a single disease activity score for different inflammatory rheumatic diseases using an intuitive scale.

\section{Key Messages}

\section{What is already known about this subject?}

Scores reflecting disease activity are specific for a single disease. The result of this fragmented process is a multitude of disease activity scores, even for a single disease.

\section{What does this study add?}

We have created a mobile application that allows any user to simply obtain the level of disease activity, regardless of the criterion used to describe it, since the application returns both the activity criterion value calculated from the physician's data and the transformed AS135 criterion value, as well as its interpretation in terms of the level of disease activity. How might this impact on clinical practice? 
This AS135 score is a very effective way to obtain the level of disease activity, regardless of the disease or the criterion used

It also allow to compare pathological activities measured via different parameters and represents a first step towards standardization of the numerous activity scores used today.

\section{Introduction}

Many clinical study groups have developed scores reflecting disease activity (1), but most of scores are specific for a single disease and do not meet the criteria of other diseases. In addition, several groups have used different approaches to evaluate the activity of the same disease. The result of this fragmented process is a multitude of disease activity scores, even for a single disease (2).

Most activity scores use a combination of patient-reported outcomes (visual analogue scales), medical examination (for example, the swollen joint count), and markers of laboratory inflammation (erythrocyte sedimentation rate (ESR) or C-reactive protein (CRP)) (3). For example, in rheumatoid arthritis (RA), ankylosing spondylitis (AS) and polymyalgia rheumatica (PMR), the most commonly used activity scores for assessing disease activity are Disease Activity Score (DAS) 28, Ankylosing Spondylitis Disease Activity Score (ASDAS) (4) and Polymyalgia Rheumatica Activity Score (PMR-AS) (5-6), respectively, but many other criteria, such as DAS44, Simplified Disease Activity Index (SDAI) and Clinical Disease Activity Index (CDAI) in RA (7) and Bath Ankylosing Spondylitis Disease Activity Index (BASDAI) in AS (8), have been developed. The differences between scoring systems are attributable both to the development of these different scores by several groups working independently and differences between the corresponding rheumatic diseases. Name similarities (e.g., consistent use of activity index/score) and structure (algebraic sum or equation generated by logistic regression) indicate collaborations with experts that have contributed to developing scores for other diseases and a desire to use previously validated scoring systems as models (9).

For rheumatologists monitoring patients with various diseases and managing multiple scores using different maximum values (9 for RA-DAS, 6.4 for AS-DAS and 60 for PMR-AS) and value thresholds to characterize different activity levels (remission and low, moderate and high activity), disease activity evaluation can be a tedious task.

We recently suggested a standardization for the cut-offs (10). Our initial standardized system produces a similarly wide range of values and facilitates the task of interpreting activity scores for various diseases. However, the formulae used in this article were not perfect as they are limited to a linear transformation on the definition domain of a pre-existing activity score. Furthermore, without a cell phone application, its possibility of use by clinicians was low. The same problem could arise in fields other than rheumatology.

Therefore, our goal was to create a universal activity score available on a mobile app to facilitate daily routine practice for specialists and even more so for non-specialists for whom it is difficult to memorize disease activity score names, items, and cut-offs and their significance.

\section{Materials And Methods}

\section{Organization of the study}

First, we conducted a review of the scientific literature on the activity criteria used to characterize inflammatory diseases. Then, we defined the AS135 score, a universal activity score based on linear interpolation converting any 
of the previously selected activity scores into AS-135. Finally, we developed a mobile application to calculate and convert the activity score of a certain disease into the AS135 score.

\section{Literature review}

Our review of the literature aimed to retrieve all activity scores used to characterize the level of activity in inflammatory diseases.

English publications published between 1.1.1975 and 31.12.2018 were selected using the following key words: "Disease activity score", "activity criteria" and "inflammatory rheumatic diseases". We extracted all disease activity scores from these publications and defined the threshold values for states of remission and low, moderate and high activity.

We had the opportunity to develop the software BIBOT (11), which assists in manual review, even in numerous or heterogeneous contexts, suggesting its place for review in this context. Written in Python 2.7 language, BIBOT was built using the Bio.Entrez and Natural Language Toolkit (NLTK) packages and uses natural language processing (a deep machine learning artificial intelligence technique) to understand texts written in English. BIBOT interacts with the MEDLINE database through the application programming interface E-utility, made available by the National Center for Biotechnology Information in 2008, and automatically identifies and interprets important words in large numbers of abstracts. Therefore, each sentence is automatically segmented into linguistic units, and the main topics identified are compared to two lists of keywords: a validation list containing relevant terms and an exclusion list of terms reflecting specific exclusion criteria. The BIBOT program has been upgraded since its last utilization (12) and is now able to classify articles in order of interest. Instead of being simply selected or rejected, the articles are divided into four different categories: Platinum, Gold, Silver and Bronze. The Platinum score corresponds to articles for which all the key words extracted from the query were directly found, the Gold score corresponds to articles that indirectly satisfy (via the use of $\mathrm{MeSH}$ ) all the key words removed from the query, the Silver score corresponds to articles for which at least one of the keywords of the query was found, and finally, the Bronze score corresponds to articles proposed by PubMed but for which none of the keywords were found. An additional text analysis was performed using BIBOT to extract the use of different activity scores within the literature by scanning the abstracts and titles of the selected publications.

Finally, a clinician (BC) performed a review of all detected articles and summarized all developed activity criteria and their thresholds.

\section{AS135 score definition}

Our goal was to build a universal activity score obtained by linear interpolation of existing scores, leading to threshold values for low, moderate and high activity states set at 1, 3 and 5, respectively. The use of these arbitrary thresholds associated with the thresholds of the existing scoring systems lead to similar activity scores.

\section{Mobile application}

Finally, we developed an Android application to calculate these AS135 scores. The application can be used to compute a typical activity score and obtain both the initial activity score and the corresponding AS135 score or to directly convert existing activity scores to a AS135 score (figure 1). This Android application is available via Google Play under the name AS135 or using the QR code shown in figure 2. 


\section{Results}

\section{Literature review}

A total of 16026 articles were analysed by BIBOT, 948 were excluded on the basis of the language in which they were written, and 2221 were excluded on the basis of their publication date. Among the remaining articles, 2241 were selected based on their titles, abstracts and keywords (annex 1). These articles were then ranked in order of relevance by the program BIBOT. We automatically extracted 10 activity scores from references that met our inclusion criteria: DAS28 (ESR), DAS28 (CRP), CDAI, SDAl, ASDAS (ESR), ASDAS (CRP), the EULAR Sjögren's syndrome (SS) Disease Activity Index (ESSDAI), the Systemic Lupus Erythematosus Disease Activity Index (SLEDAI2K), Disease Activity in PSoriatic Arthritis (DAPSA), PMR-AS (ESR) and PMR-AS (CRP) (table 1). These activity scores cover 7 different pathologies in the field of rheumatology: RA, AS, Sjögren's syndrome (SjS), systemic lupus erythematosus (SLE), psoriatic arthritis (PSA) and PMR. Only a few scores in medical fields outside rheumatology may be adaptable for the AS135 scoring system (table 2).

DAS28 was mentioned in 1227 abstracts, SDAl was mentioned in 196 abstracts, and ASDAS-CRP was mentioned in 13 abstracts (Annex 2). Therefore, DAS 28 was the most frequently used activity criterion in RA, but two variants, DAS28-CRP (350 abstracts) and DAS28-ESR (269 abstracts), were also used. We compared their use in the literature from 2004 to 2018 to determine whether one of them became predominant in the literature. Although a tendency for the use of DAS28-CRP in 2013 and 2014 was observed, DAS28-CRP and DAS28-ESR were indiscriminately used over time, justifying that we include both in the AS135.

\section{AS135 score equation}

The AS135 score is defined as a universal activity score obtained by the linear interpolation of existing scores. Threshold values for low, moderate and high activity states were set at 1, 3 and 5 , respectively, to reflect the range typically used for each activity state in existing activity scores: these scores generally separate into four groups such that remission exhibits the smallest interval, low and moderate activity exhibit quite similar intervals (for example, lower than 1.5 for PMR-AS), and high activity exhibits the greatest interval (for example, 17 to 50 for PMR-AS). These arbitrary thresholds are then associated with the thresholds for the existing scoring system, and an interpolation can be calculated. In this way, it is possible to compare the activity scores defined on different domains from different parameters by converting these scores into AS135 scores, which are defined on an intuitive scale: $[0,10]($ equation 1 , table 3), where $x$ is the value of the original score to be converted, while $a$ and $b$ are the nearest thresholds of $x$ such that and.

\section{Example of application of the AS135 in Rheumatoid Arthritis}

To illustrate application of the AS135 score, consider the following hypothetical situation: two patients have RA, and their disease activities were calculated based on different information. The first patient, $p_{1}$, has a DAS28 score of 6.7, while the second, $p_{2}$ has an SDAI score of 25. Comparing the pathological activities in $p_{1}$ and $p_{2}$ does not seem to be a very intuitive task based on this information alone. The conversion of these scores to AS135 proceeds as follows: the equation of the conversion is set for patient $p_{1}$ (equation 2 , table 2), with the thresholds $a=5.2$ and $b=$ 9.1 defined for the DAS28 score, corresponding to the high activity threshold and maximum value adopted by the DAS28 score, respectively, and because by definition $A S 135$ (threshold $\left._{\text {high }}\right)=5$ and $A S 135\left(\right.$ threshold $\left._{\text {max }}\right)=10$, equation 2 can be expanded, and the value $A S 135\left(\mathrm{p}_{1}\right)$ can be calculated (equation 3 , table 2 ). The same reasoning is used with patient $p_{2}$ by adopting the values $a=11$ and $b=26$, corresponding to the thresholds of moderate and high 
activity by the SDAI score. Because by definition $A S 135$ (threshold moderate $)=3$ and $A S 135\left(\right.$ threshold $\left._{\text {high }}\right)=5$, the equation for patient $p_{2}$ can be written as equation 4 (table 2). Thus, we finally obtain the score $A S 135\left(p_{1}\right)=6.92$ and score $A S 135\left(p_{2}\right)=4.8$ defined on the same interval $[0,10]$. Patient $p_{1}$ is thus described as having high disease activity (since $A S 135\left(p_{1}\right)>5$ ), and patient $p_{2}$ is characterized by moderate activity $\left(\right.$ since $\left.\left.3<A S 135\left(p_{2}\right)\right)<5\right)$.

\section{Example of association between AS135 and PMR-AS in polymyalgia rheumatica}

Figure 3 shows in the Tenor study, which evaluated patients with polymyalgia rheumatica at different visits (9), the link between AS135 and PMR-AS. All patients are, as expected, classified similarly by the AS135 and the PMR-AS.

\section{Discussion}

We developed a mobile application that allows us to obtain disease activity, regardless of the criterion used by transformation of any value into the AS135 criterion. This is a first step towards the standardization of activity scores used in rheumatic diseases.

A literature review focused on finding disease activity scores in inflammatory rheumatism because many activity scores are used to describe them (13). Some of these scores are the subject of a perfect consensus on the definition of the threshold values for the activity levels of disease. This is essential for the process of conversion into an AS135 score and is not frequently possible in other medical fields. Furthermore, this allows us to define 4 separate levels of disease activity based on score: remission and low, moderate and high activity. The mathematical model used for the conversion is based on values corresponding to the activity thresholds for the selected scores. These thresholds are identified and therefore predetermined, the conversion does not involve any complex calculation and can be run very easily on any computer or mobile device. Thus, we first prioritized the three most commonly used scores in RA.

The application that we have developed makes it possible to convert any of the 10 activity scores selected with the literature review into a universal AS135 score. Because this conversion was built around a linear interpolation, it is possible to consider this transformation as a bijection and to therefore use the AS135 score as an intermediary between two scores to project the value of the first on the definition range of the second. In practice, we limit ourselves to the conversion of the scores into an AS135 value to take advantage of the intuitive definition field of this universal score. This application will provide clinicians with a quick tool to convert the main scores used in rheumatology to the AS135 score and thus allow clinicians to access the level of disease activity, even without knowledge of the thresholds used for a specific score.

Our use of BIBOT, which is not a classic systematic method to review the literature, for the literature review is a potential limitation, but we previously demonstrated that this software is at least as efficient as a manual systematic literature review and that the combination of BIBOT and manual review is the best way to conduct a literature review (12). Another limitation of the study is the use of a linear model to approximate the distribution of each score, but selected scores have been constructed to be interpreted as a linear scale, which makes the approximation performed by AS135 very acceptable

We noticed that communication between rheumatologists and primary care physicians can sometimes be altered by scores that are too specific, especially because of thresholds that differ from one score to another. Although it may be frustrating for rheumatologists to turn from their currently employed daily scores, the AS135 is an adequate tool 
that establishes a common language for all practitioners with universal and easily remembered limits. The same reasoning will allow more fluent communication between different specialists.

Furthermore, this unique score is appropriate for rheumatologists who currently use several common scores to present a simplified follow-up of disease activity. Furthermore, this scoring system would allow practitioners to switch from one score to another according to the specific situation (e.g., DAS44 to DAS28, BASDAI to ASDAS), while keeping the same quantitative base with immovable thresholds.

The same way of thinking, i.e., the projection on a universal activity score, seems to be applicable in some other medical specialties that use well-defined scores. Fields such as dermatology (SCORAD in atopic dermatitis (19), ABSIS and Pemphigus Disease Area Index (PDAI) for pemphigus $(20,21)$, the Psoriasis Area and Severity Index (PASI) for psoriasis (22)), gastroenterology (Crohn's Disease Activity Index (CDAI)-Best, Harvey-Bradshaw and the Perianal Crohn's Disease Activity Index (PCDAI) for Crohn's disease (23-25) and the Ulcerative Colitis Disease Activity Index (UC-DAl) for ulcerative colitis (26)) and psychiatry (Patient Health Questionnaire (PHQ-9) score to estimate depression level (27)) could be interested in the use of a more accessible scoring system.

In conclusion, we have created a mobile application that allows any user to simply obtain the level of disease activity, regardless of the criterion used to describe it, since the application returns both the activity criterion value calculated from the physician's data and the transformed AS135 criterion value, as well as its interpretation in terms of the level of disease activity. This AS135 score is a very effective way to compare pathological activities measured via different parameters and represents a first step towards standardization of the numerous activity scores used today. The application we developed is now available for Android devices, and we plan to start developing a version for iOS devices in the near future.

\section{Declarations}

\section{Competing interests : None}

Contributorship : Alain Saraux and Nathan Foulquier designed the study, wrote the first draft of the manuscript, advised on data analysis, advised on interpreting data, and revised the report. Baptiste Chevet, Guillermo Carvajal Alegria, Léa Saraux, Valérie Devauchelle-Pensec, Pascal Redou collected data, advised on data analysis, advised on interpreting data, and revised the report.

Funding info : No funding

Ethical approval information : Not applicable

Data sharing statement : Patients were not involved in this study

\section{References}

1. Rhind V, Bird HA, Wright V. A Comparison of Clinical Assessments of Disease Activity in Rheumatoid Arthritis. Ann Rheum Dis. Ann Rheum Dis, 198039(2):135-137.

2. Kerschbaumer A, Smolen JS, Aletaha D. Disease activity assessment in patients with psoriatic arthritis. Best Pract Res Clin Rheumatol. 2018,32(3):401-14.

3. Prevoo ML, van 't Hof MA, Kuper HH, van Leeuwen MA, van de Putte LB, van Riel PL. Modified disease activity scores that include twenty-eight-joint counts. Development and validation in a prospective longitudinal study of 
patients with rheumatoid arthritis. Arthritis Rheum. janv 1995,38(1):44-8.

4. Lukas C, Landewé R, Sieper J, Dougados M, Davis J, Braun J, et al. Development of an ASAS-endorsed disease activity score (ASDAS) in patients with ankylosing spondylitis. Ann Rheum Dis. janv 2009,68(1):18-24.

5. Leeb BF, Bird HA. A disease activity score for polymyalgia rheumatica. Ann Rheum Dis. oct 2004,63(10):127983.

6. Binard A, de Bandt M, Berthelot J-M, Saraux A, Inflammatory Joint Disease Working Group of the French Society for Rheumatology. Performance of the polymyalgia rheumatica activity score for diagnosing disease flares. Arthritis Rheum. 15 févr 2008,59(2):263-9.

7. Aletaha D, Nell VPK, Stamm T, Uffmann M, Pflugbeil S, Machold K, et al. Acute phase reactants add little to composite disease activity indices for rheumatoid arthritis: validation of a clinical activity score. Arthritis Res Ther. 2005,7(4):R796-806.

8. Garrett S, Jenkinson T, Kennedy LG, Whitelock H, Gaisford P, Calin A. A new approach to defining disease status in ankylosing spondylitis: the Bath Ankylosing Spondylitis Disease Activity Index. J Rheumatol. déc 1994,21(12):2286-91.

9. Devauchelle-Pensec V, Saraux L, Berthelot JM, De Bandt M, Cornec D, Guellec D, et al. Assessing polymyalgia rheumatica activity when C-reactive protein is unavailable or uninterpretable. Rheumatology (Oxford). 01 2018,57(4):666-70.

10. Saraux L, Devauchelle-Pensec V, Saraux A. Plea for standardization of disease activity scores. Rheumatology. 1 août 2019,58(8):1500-1.

11. Foulquier N, Redou P, Le Gal C, Rouvière B, Pers J-O, Saraux A. Pathogenesis-based treatments in primary Sjogren's syndrome using artificial intelligence and advanced machine learning techniques: a systematic literature review. Hum Vaccin Immunother. 2018,14(11):2553-8.

12. Orgeolet L, Foulquier N, Misery L, Redou P, Pers, Jacques-Olivier P, Devauchelle-Pensec V, et al. Can Artificial Intelligence Replace Manual Search for Systematic Literature? Review on Cutaneous Manifestations in Primary Sjögren's Syndrome [Internet]. Vol. 59, Rheumatology (Oxford, England). Rheumatology (Oxford), 2020,59(4):811-819

13. England BR, Tiong BK, Bergman MJ, Curtis JR, Kazi S, Mikuls TR, et al. 2019 Update of the American College of Rheumatology Recommended Rheumatoid Arthritis Disease Activity Measures. Arthritis Care Res (Hoboken). 2019,71(12):1540-55.

14. Wells G, Becker J-C, Teng J, Dougados M, Schiff M, Smolen J, et al. Validation of the 28-joint Disease Activity Score (DAS28) and European League Against Rheumatism response criteria based on C-reactive protein against disease progression in patients with rheumatoid arthritis, and comparison with the DAS28 based on erythrocyte sedimentation rate. Ann Rheum Dis. juin 2009,68(6):954-60.

15. Smolen J, Breedveld FC, Schiff M, Kalden K, Emery P, Eberl G, et al. A Simplified Disease Activity Index for Rheumatoid Arthritis for Use in Clinical Practice [Internet]. Vol. 42, Rheumatology (Oxford, England). Rheumatology (Oxford), 2003 42(2):244-57.

16. Schoels M, Aletaha D, Funovits J, Kavanaugh A, Baker D, Smolen JS. Application of the DAREA/DAPSA score for assessment of disease activity in psoriatic arthritis. Ann Rheum Dis. août 2010,69(8):1441-7.

17. Ramsey Goldman R, Isenberg DA. Systemic lupus erythematosus measures: British Isles Lupus Assessment Group (BILAG), European Consensus Lupus Activity Measurement (ECLAM), Systemic Lupus Activity Measure (SLAM), Systemic Lupus Erythematosus Disease Activity Measure (SLEDAI), and Systemic Lupus International 
Collaborating Clinics/American College of Rheumatology-Damage Index (SLICC/ACR-DI, SDI). Arthritis Care \& Research. 2003,49(S5):S225-33.

18. Seror R, Bowman SJ, Brito-Zeron P, Theander E, Bootsma H, Tzioufas A, et al. EULAR Sjögren's syndrome disease activity index (ESSDAl): a user guide. RMD Open. 1 févr 2015,1(1):e000022.

19. Severity scoring of atopic dermatitis: the SCORAD index. Consensus Report of the European Task Force on Atopic Dermatitis. Dermatology (Basel). 1993,186(1):23-31.

20. Pfütze M, Niedermeier A, Hertl M, Eming R. Introducing a novel Autoimmune Bullous Skin Disorder Intensity Score (ABSIS) in pemphigus. Eur J Dermatol. févr 2007,17(1):4-11.

21. Boulard C, Duvert Lehembre S, Picard-Dahan C, Kern JS, Zambruno G, Feliciani C, et al. Calculation of cut-off values based on the Autoimmune Bullous Skin Disorder Intensity Score (ABSIS) and Pemphigus Disease Area Index (PDAl) pemphigus scoring systems for defining moderate, significant and extensive types of pemphigus. Br J Dermatol. juill 2016,175(1):142-9.

22. Fredriksson T, Pettersson U. Severe psoriasis--oral therapy with a new retinoid. Dermatologica. 1978,157(4):23844.

23. Best WR, Becktel JM, Singleton JW, Kern F. Development of a Crohn's disease activity index. National Cooperative Crohn's Disease Study. Gastroenterology. mars 1976,70(3):439-44.

24. Harvey RF, Bradshaw JM. A simple index of Crohn's-disease activity. Lancet. 8 mars 1980,1(8167):514.

25. Hyams JS, Ferry GD, Mandel FS, Gryboski JD, Kibort PM, Kirschner BS, et al. Development and validation of a pediatric Crohn's disease activity index. J Pediatr Gastroenterol Nutr. mai 1991,12(4):439-47.

26. Schroeder KW, Tremaine WJ, Ilstrup DM. Coated oral 5-aminosalicylic acid therapy for mildly to moderately active ulcerative colitis. A randomized study. N Engl J Med. 24 déc 1987,317(26):1625-9.

27. Kroenke K, Spitzer RL, Williams JB. The PHQ-9: validity of a brief depression severity measure. J Gen Intern Med. sept 2001,16(9):606-13.

\section{Tables}

Table 1: Disease activity scores included in the AS135 


\begin{tabular}{|c|c|c|c|c|c|c|}
\hline Score & Formulae & Remission & Low activity & $\begin{array}{l}\text { Moderate } \\
\text { activity }\end{array}$ & $\begin{array}{l}\text { High } \\
\text { activity }\end{array}$ & Disease \\
\hline $\begin{array}{l}\text { DAS28- } \\
\text { ESR }\end{array}$ & $\begin{array}{rl}0.56 * \sqrt{T J}+0.28 & * \sqrt{S J}+0.70 \\
& * \ln (E S R)+0.014 \\
& * G H_{\text {patient }}\end{array}$ & $<2.6$ & $2.6 \leq$ Score $\leq 3.2$ & $\begin{array}{l}3.2< \\
\text { Score } \leq 5.1\end{array}$ & $>5.1$ & RA \\
\hline $\begin{array}{l}\text { DAS28- } \\
\text { CRP }\end{array}$ & $\begin{array}{rl}0.56 * \sqrt{T J}+0.28 & * \sqrt{S J}+0.36 \\
& * \ln (C R P+1) \\
& +0.014 \\
& * G H_{\text {patient }}\end{array}$ & $<2.6$ & $2.6 \leq$ Score $\leq 3.2$ & $\begin{array}{l}3.2< \\
\text { Score } \leq 5.1\end{array}$ & $>5.1$ & RA \\
\hline SDAl & $\begin{array}{l}S J+T J+G H_{\text {patient }}+G H_{\text {clinicien }}+ \\
\mathrm{CRP}\end{array}$ & $\leq 3.3$ & $3.3<$ Score $\leq 11$ & $\begin{array}{l}11< \\
\text { Score } \leq 26\end{array}$ & $>26$ & RA \\
\hline CDAI & $S J+T J+G H_{\text {patient }}+G H_{\text {clinicien }}$ & $\leq 2.8$ & $2.8<$ Score $\leq 10$ & $\begin{array}{l}10<\text { Score } \leq \\
22\end{array}$ & $>22$ & RA \\
\hline DAPSA & $T J+S J+C R P+$ Activity + Pain & $\leq 4$ & $4<$ Score $\leq 14$ & $\begin{array}{l}14<\text { Score } \leq \\
28\end{array}$ & $>28$ & PsA \\
\hline $\begin{array}{l}\text { ASDAS } \\
\text { CRP }\end{array}$ & $\begin{array}{rl}0.12 * B P+0.06 & * M F D+0.11 \\
& * P D+0.07 * P J P \\
& +0.58 \\
& * \ln (C R P+1)\end{array}$ & $\leq 1.3$ & $\begin{array}{l}1.3< \\
\text { Score } \leq 2.1\end{array}$ & $\begin{array}{l}2.1< \\
\text { Score } \leq 3.5\end{array}$ & $>3.5$ & SpA \\
\hline $\begin{array}{l}\text { ASDAS } \\
\text { ESR }\end{array}$ & $\begin{array}{rl}0.88 * B P+0.06 & * M F D+0.11 \\
& * P D+0.09 * P J P \\
& +0.29 * \sqrt{E S R}\end{array}$ & $\leq 1.3$ & $1.3<$ Score $\leq 2.1$ & $\begin{array}{l}2.1< \\
\text { Score } \leq 3.5\end{array}$ & $>3.5$ & SpA \\
\hline $\begin{array}{l}\text { SLEDAI- } \\
2 \mathrm{~K}\end{array}$ & See article (17) & 0 & $0<$ Score $\leq 5$ & $\begin{array}{l}6 \leq \text { Score } \leq \\
10 \$\end{array}$ & $>10$ & SLE \\
\hline ESSDAI & See article (18) & 0 & $0<$ Score $<5$ & $\begin{array}{l}5 \leq \text { Score } \leq \\
13\end{array}$ & $>13$ & SjS \\
\hline $\begin{array}{l}\text { PMR-AS } \\
\text { CRP }\end{array}$ & $\begin{array}{l}C R P+G H_{\text {patient }}+G H_{\text {clinicien }}+ \\
0.1 * M F D+E U L\end{array}$ & $\leq 1.5$ & $1.5<$ Score $<7$ & $7 \leq$ Score $\leq 17$ & $>17$ & PMR \\
\hline $\begin{array}{l}\text { PMR-AS } \\
\text { ESR }\end{array}$ & $\begin{aligned} E S R+G H_{\text {patient }} & +G H_{\text {clinicien }}+0.1 \\
& * M F D+E U L\end{aligned}$ & $\leq 1.5$ & $1.5<$ Score $<7$ & $7 \leq$ Score $\leq 17$ & $>17$ & PMR \\
\hline
\end{tabular}

DAS 28: Disease Activity Score, SDAl: Simplified Disease Activity Index, CDAl: Clinical Disease Activity Index, DAPSA: Disease Activity in PSoriatic Arthritis, ASDAS: Activity Index Ankylosing Spondylitis Disease Activity Score, SLEDAI-2K: Systemic Lupus Erythematosus Disease Activity Index, ESSDAI: EULAR Sjögren's Syndrome Disease Activity Index, Polymyalgia Rheumatica Activity Score (PMR-AS)

TJ: tender joint count, SJ: swollen joint count, ESR: erythrocyte sedimentation rate, $\mathrm{GH}_{\text {patient }}$ global assessment of health by the patient, $\mathrm{GH}_{\text {clinician: }}$ overall assessment of health by the clinician, CRP: C-reactive protein, BP: back pain, MFD: duration of morning stiffness, PD: discomfort felt by the patient, PJP: peripheral pain, EUL: elevation ability of the upper limbs,

RA: rheumatoid arthritis, PA: psoriatic arthritis, SpA: ankylosing spondylitis, SLE: systemic lupus erythematosus, SjS: Sjögren's syndrome, PMR: polymyalgia rheumatica. 
Table 2: Disease activity scores in medical fields outside rheumatology that may be adaptable for the AS135

\begin{tabular}{|c|c|c|c|c|c|c|}
\hline Score & Reference & Remission & $\begin{array}{l}\text { Low } \\
\text { activity }\end{array}$ & Moderate activity & High activity & $\begin{array}{l}\text { Disease/ } \\
\text { Medical field }\end{array}$ \\
\hline \multirow[t]{2}{*}{ SCORAD } & 19 & - & Score $<15$ & $15 \leq$ Score $<40$ & Score $\geq 40$ & Atopic dermatitis \\
\hline & & & & & & Dermatology \\
\hline \multirow[t]{2}{*}{ ABSIS } & 20 & - & Score $<17$ & $17 \leq$ Score $<53$ & - & Pemphigus \\
\hline & & & & & & Dermatology \\
\hline \multirow[t]{2}{*}{ PDAI } & 21 & - & Score $<15$ & $15 \leq$ Score $<45$ & - & Pemphigus \\
\hline & & & & & & Dermatology \\
\hline \multirow[t]{2}{*}{ PASI } & 22 & - & Score $\leq 5$ & $5<$ Score $\leq 12$ & $12<$ Score $\leq$ & Psoriasis \\
\hline & & & & & $\frac{\text { activity: Score }}{>20)}$ & Dermatology \\
\hline \multirow[t]{2}{*}{ CDAl-Best } & 23 & $\begin{array}{l}\text { Score } \leq \\
150\end{array}$ & $\begin{array}{l}150< \\
\text { Score < }\end{array}$ & $220 \leq$ Score $\leq 450$ & Score $>450$ & Crohn's disease \\
\hline & & & 220 & & & Gastroenterology \\
\hline \multirow{2}{*}{$\begin{array}{l}\text { Harvey- } \\
\text { Bradshaw }\end{array}$} & 24 & Score $<4$ & - & $4 \leq$ Score $\leq 12$ & Score $>12$ & Crohn's disease \\
\hline & & & & & & Gastroenterology \\
\hline \multirow[t]{2}{*}{ PCDAI } & 25 & - & Score $\leq 10$ & $10<$ Score $\leq 19$ & Score $\geq 20$ & Crohn's disease \\
\hline & & & & & & Gastroenterology \\
\hline \multirow[t]{2}{*}{ UC-DAI } & 26 & Score $\leq 2$ & $\begin{array}{l}2< \\
\text { Score }<5\end{array}$ & $5<$ Score $\leq 10$ & Score $\geq 11$ & Ulcerative Colitis \\
\hline & & & & & & Gastroenterology \\
\hline \multirow[t]{2}{*}{ PHQ-9 } & 27 & Score $\leq 4$ & $\begin{array}{l}4< \\
\text { Score }<9\end{array}$ & $9<$ Score $\leq 14$ & $\begin{array}{l}14< \\
\text { Scoro }<19\end{array}$ & Depression \\
\hline & & & & & $\begin{array}{l}\text { (Very high } \\
\text { activity: Score } \\
\geq 20)\end{array}$ & Psychiatry \\
\hline
\end{tabular}

Table 3: A set of equations to illustrate how the AS135 works: equation 1 is the general model behind AS135, equations 2 to 4 are examples illustrating the conversion of a score from DAS28 to AS135 (equation 3) and from SDAI to AS135 (equation 4). 


\begin{tabular}{|l|c|}
\hline Equation 1 & $A S 135(x)=A S 135(a)+(A S 135(b)-A S 135(a)) * \frac{x-a}{b-a}$ \\
\hline Equation 2 & $A S 135\left(p_{1}\right)=A S 135(6.7)=A S 135(5.2)+(A S 135(9.1)-A S 135(5.2)) * \frac{6.7-5.2}{9.1-5.2}$ \\
\hline Equation 3 & $A S 135(6.7)=5+(10-5) * \frac{6.7-5.2}{9.1-5.2}$ \\
& $A S 135(6.7)=6.92$ \\
\hline Equation 4 & $S 135(25)=3+(5-3) * \frac{25-11}{26-11}$ \\
& $A S 135(25)=4.8$ \\
\hline
\end{tabular}

\section{Figures}




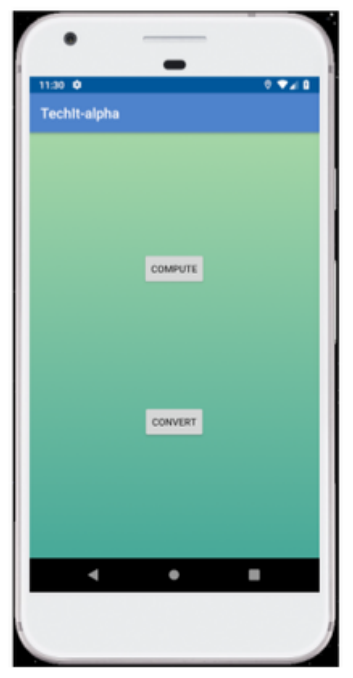

a)

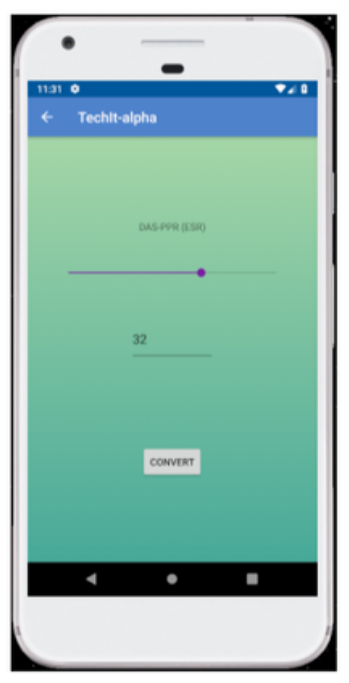

d)

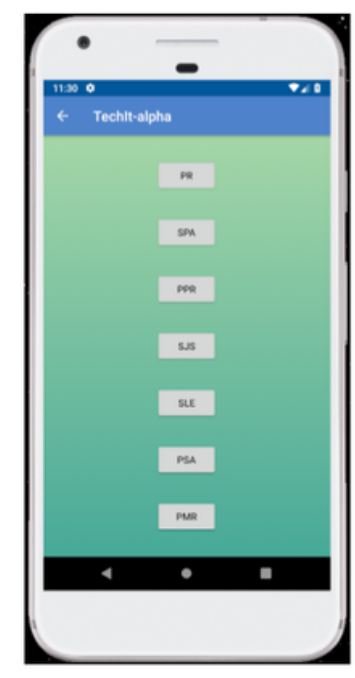

b)

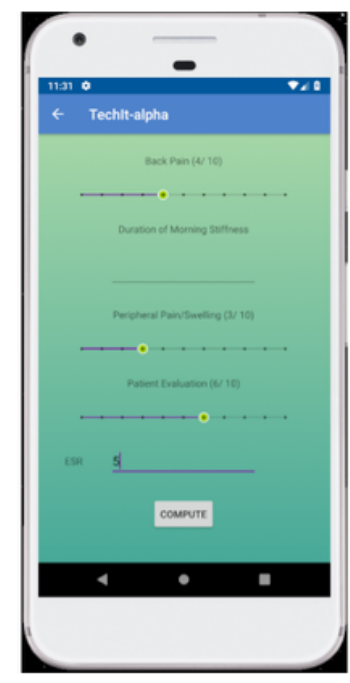

f)

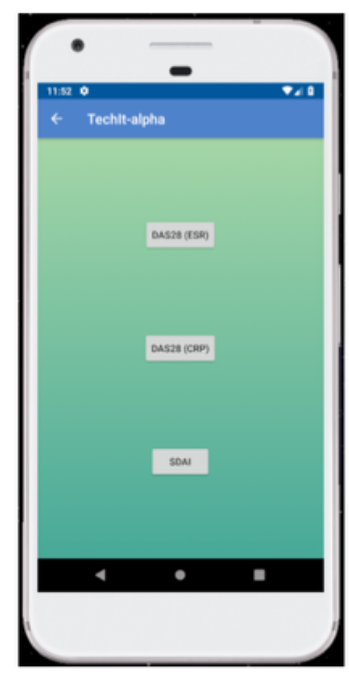

c)

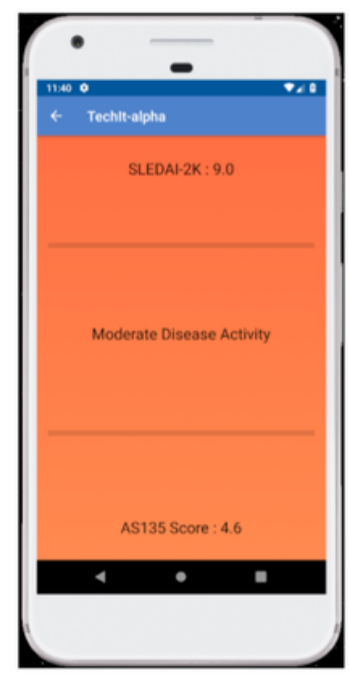

g)

Figure 1

Different screens of the AS135 application. The first line corresponds to the selection screens for the operation (a), disease (b), and score to be processed (c). The second line shows the screen for converting an existing score to an AS135 score (d), the screen for calculating a new score (e) and the screen that presents the results (f). 


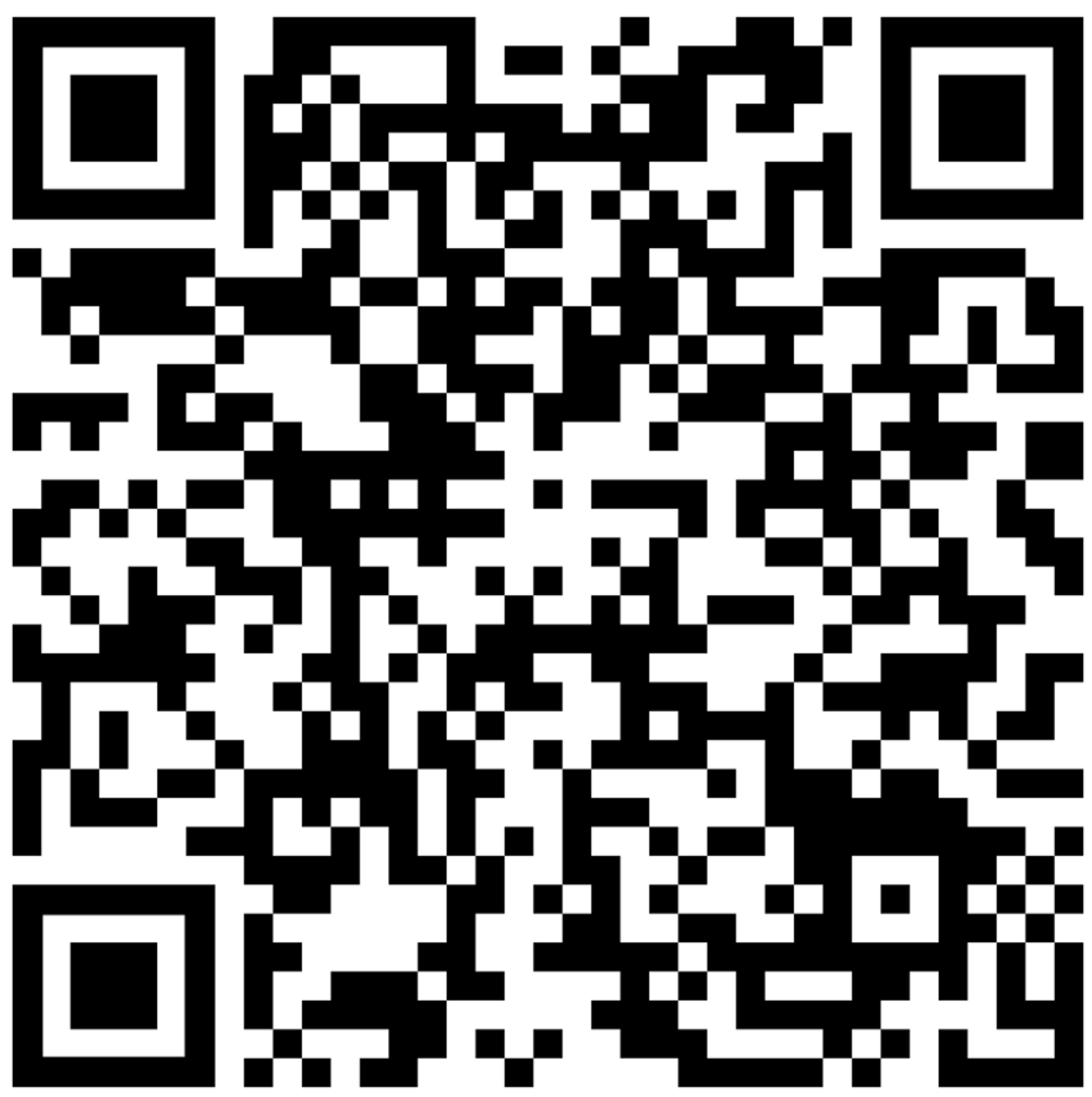

Figure 2

QR code to obtain the AS135 


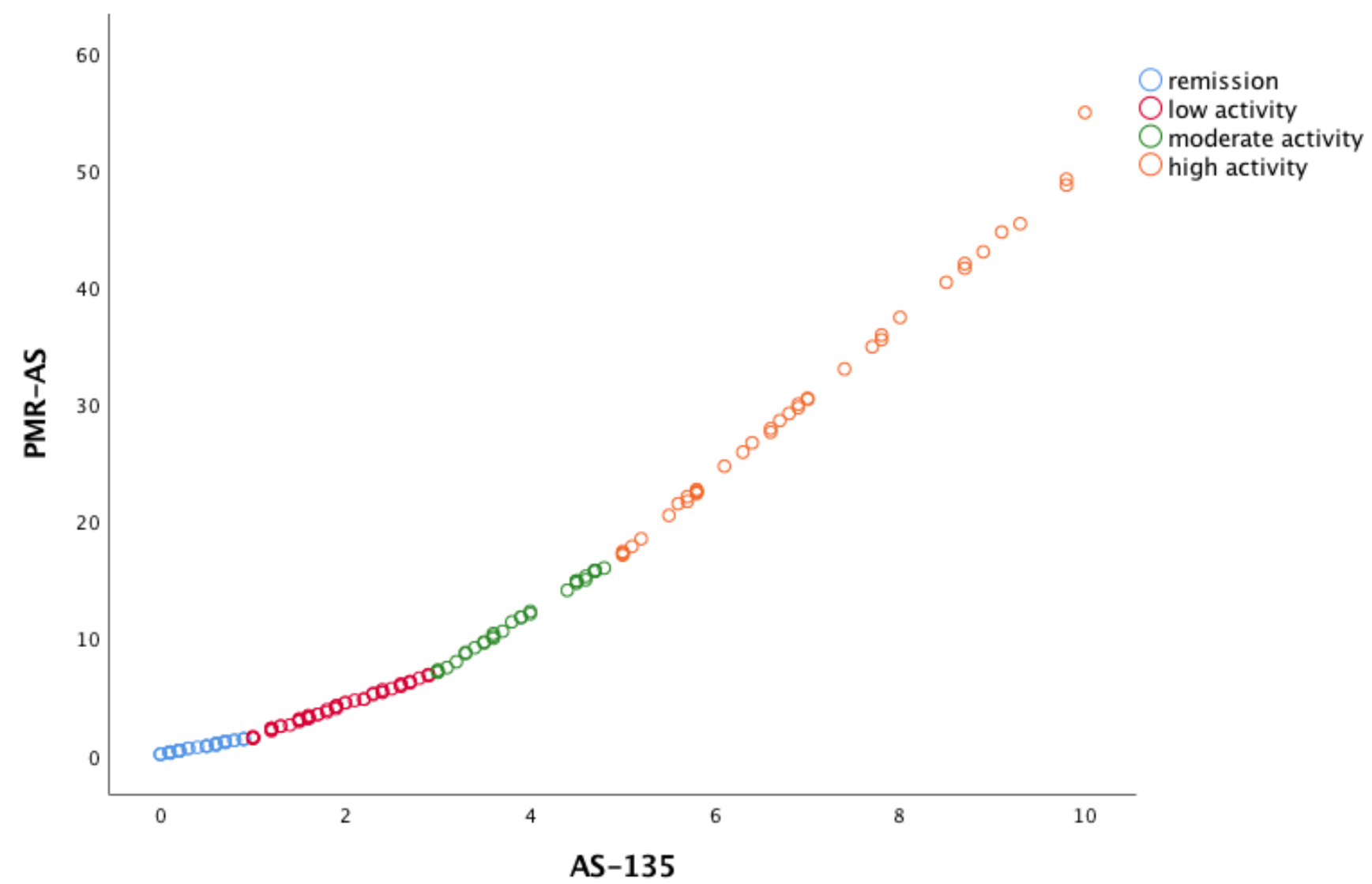

Figure 3

Association between AS135 and PMR-AS in polymyalgia rheumatica 